\title{
PERINATAL DEATH AUDIT
}

\author{
Dali S M*, Tuladhar H, Pradhan P*, Awale P*, Thapa $S^{*}$
}

\section{ABSTRACT}

This retrospective study was conducted to find out the status of perinatal mortality at Nepal Medical College Teaching Hospital (NMCTH) which is located at sub-urban area of Kathmandu. Records of all consecutive deliveries from 1/7/1998 to 30/12/2002 were reviewed. Total number of deliveries was 1517 among which 1182(77.9\%)were normal deliveries. Total number of birth was 1531 including 14 set of twins. There were 38 still birth (24.8 per 1000 birth) and 7 early neonatal deaths (4.7 per 1000 live birth). The perinatal mortality rate was 29.4 per 1000 birth. Perinatal mortality was higher in low birth weight babies (77\%) and premature (173.2\%). Most of the cases (46.7\%) have not attended regular Ante-natal Checkup (ANC). Among 38 cases of still birth, 27 were macerated. Abruptio placenta and pregnancy induced hypertension were common identifiable causes of Intra-uterine Death (IUD), whereas among 7 cases of Early Neonatal Death (ENND), 4 cases were due to pre-maturity with hyaline membrane disease. Regular ante natal care with identification of high risk group and management of complications along with improved neonatal care facilities will help to minimize the high perinatal mortality rate. Regular perinatal death audit is necessary to identify the common and preventable causes of perinatal mortality.

\section{Key Words: Perinatal death audit, Perinatal mortality.}

\section{INTRODUCTION}

Perinatal Mortality Rate (PMR) is markedly reduced in developed countries since last two decades. PMR gives an idea of standard of perinatal services available there The PMR vary from less than 10 in Japan and Germany to as high as 80 or even 100/1000 births in the least developed countries. The most developing countries have rates around 35 to 60 per $1000 .^{2}$ The important obstetric causes of perinatal deaths are prolonged/difficult labour, antepartum haemorrhage, hypertensive diseases of pregnancy, chronic maternal diseases and congenital abnormalities. In about a third of these cases, no cause is found. The leading factors among fetal and neonatal causes of perinatal mortality are birth asphyxia/trauma, prematurity, congenital malformation and infections, ${ }^{4,5,6,7}$ Factors influencing the perinatal mortality rates are maternal age, parity, number of antenatal visits, maternal health and socioeconomic status.

\section{OBJECTIVES}

- To review the perinatal mortality statistics which will help to evaluate and improve the existing obstetric and neonatal services in this hospital.

- To detect the causes and preventable factors in perinatal deaths, so that recommendations can be made to reduce the perinatal mortality.

* Nepal Medical College \& Teaching Hospital, Jorpati, Kathmandu, Nepal.

Address for correspondence : Prof. Sanu Maiya Dali

Email: visavila@ccsl.com.np 


\section{MATERIALS AND METHODS}

This is a retrospective analysis of the records of all deliveries conducted at Nepal Medical College Teaching Hospital from 1/ 7/ 1998 to 30/ 12/2002 .Nepal Medical College is situated at Attarkhel of Jorpati VDC, in Kathmandu about $11 \mathrm{KM}$ Northeast of Kathmandu center It is situated about $4 \mathrm{Kms}$. from Bouddhanath Stupa on the way to sundarijal. NMC campus comprises of the college with 525 bed Nepal Medical College Teaching Hospital of which 90 beds are allocated to Department of Obstetrics and gynaecology. The records of early neonatal deaths were reviewed from department of neonatology. The births before 28 completed gestational weeks were excluded. For analysis of contributory factors, maternal age, parity, antenatal visits, gestational age, birth weight, antenatal and neonatal complications were recorded.

\section{LIMITATIONS OF STUDY}

Because of retrospective study, some of the data were not complete, hence maternal anaemia, malnutrition, cephalopelvic disproportion, prolonged labor etc. could not be correlated with perinatal mortality.

Autopsy was not performed in these cases. Perinatal autopsy findings would have been valuable for accurate diagnosis and correlation of clinical findings especially in those cases where obvious causes not be found.

\section{RESULTS}

\section{The Results of Study are as follows:}

Total number of deliveries was 1517 , among which $77.9 \%$
(1182) was spontaneous vaginal delivery, LSCS rate was $8.9 \%$ (135). Total number of births was 1531 including 14 sets of twins. $2.59 \%$ (44) cases had forceps and vaccum extraction. $0.9 \%$. 15 cases had breech delivery and 8.4\% (127) cases had premature deliveries were $127(8.4 \%)$.

Out of 1531 total births, 38 were still born and 7 were early neonatal deaths. Perinatal mortality rate was 29.4 and the extended perinatal mortality rate was 32.6 per 1000 births.

Perinatal mortality rate seemed to be higher in adolescent age group and elderly mothers. The incidence of adolescents pregnancy (15 to 19 years) was $11.6 \%$ (176 cases). The perinatal mortality rate in adolescents was 51.1 per 1000 births. Whereas in the age group 20 to 29 years, the rate was only 20.4/ 1000 birth ( 25 perinatal deaths among 1223 cases, The highest perinatal mortality rate was seen in age group $>30$ years i. e. 93.2/ 1000births ( 11 deaths in 118 cases).

Perinatal mortality rate was more in primi gravida.

Perinatal mortality rate is lowest when gestational age is more than 37 weeks. The rate of premature delivery was $8.4 \%$ (127 cases), among them PMR was 173.2 per 1000 births which is very high as compared to term babies i.e. 16.5.

In extremely premature babies PMR was highest.

Perinatal death rate gradually decreases with increasing birth weight. The rate of low birth weight babies $(<2.5 \mathrm{Kg})$ was $31.7 \%$ (481 cases) among whom the PNR was as high as 77 per 1000 births. All cases of ENND were below $2.5 \mathrm{Kg}$.

Table I : Number of birth, perinatal death and mortality rate

\begin{tabular}{|c|c|}
\hline Statistics & Total \\
\hline Total birth & 1531 \\
\hline Total live birth & 1493 \\
\hline Still birth & 38 \\
\hline Early neonatal death & 7 \\
\hline Perinatal death & 45 \\
\hline Extended perinatal death & 50 \\
\hline Still birth rate (per 1000 birth) & 24.8 \\
\hline Early neonatal death rate (per 1000 live births) & 4.7 \\
\hline Perinatal mortality rate (per 1000 births) & 29.4 \\
\hline Extended perinatal mortality rate & 32.6 \\
\hline
\end{tabular}

Table II : The Relation of Perinatal Death To Birth Weight

\begin{tabular}{c|c|c|c|c}
\hline Weight & Still Birth & ENND & Deliveries & PNMR \\
\hline$<1000$ gm & 5 & 0 & $9(0.6 \%)$ & 555.5 \\
\hline $1000-1500$ & 7 & 3 & $48(3.2 \%)$ & 208.3 \\
\hline $1600-2000$ & 8 & 1 & $92(6.1 \%)$ & 97.8 \\
\hline $2100-2500$ & 13 & 3 & $332(21.9 \%)$ & 4.8 \\
\hline $2600+$ & 5 & 0 & $1036(68.2 \%)$ & 4.8 \\
\hline Total & $\mathbf{3 8}$ & $\mathbf{7}$ & $\mathbf{1 5 1 7}$ & $\mathbf{2 9 . 4}$ \\
\hline
\end{tabular}


Table III : Causes of still birth

\begin{tabular}{l|c}
\hline \multicolumn{1}{c|}{ Causes of Still Birth } & No. (Percentage) \\
\hline Abruptio Placenta & $5(13.1 \%)$ \\
\hline Pregnancy induced hypertension & $6(15.8 \%)$ \\
\hline Hyperpyrexia & $1(2.6 \%)$ \\
\hline Gross congenital anomaly & $2(5.3 \%)$ \\
\hline Birth asphyxia with breech & $4(10.5 \%)$ \\
Cord prolapse & $2(5.3 \%)$ \\
Unknown cause $\quad 18(47.4 \%)$ \\
\multicolumn{1}{c}{ Total } & $\mathbf{3 8}(\mathbf{1 0 0 \%})$ \\
\hline
\end{tabular}

Table IV : Causes of Early Neonatal Death

\begin{tabular}{l|c}
\hline \multicolumn{1}{c|}{ Causes } & No. (Percentage) \\
\hline Prematurity with hyaline membrane & $4(57.1 \%)$ \\
\hline Disease of lungs & $1(14.3 \%)$ \\
Neonatal septicemia & $2(28.6 \%)$ \\
Meconium aspiration & $\mathbf{7 ( 1 0 0 \% )}$ \\
\hline \multicolumn{2}{c}{ Total }
\end{tabular}

The total still births were 38 among which 11 were fresh and 27 were macerated. The causes are shown in the Table III.

Abruption placenta and pregnancy induced hypertension were the most common causes of still births. In 18 cases, no cause could be found, all these cases were intrauterine deaths and macerated still birth. Among 38 still birth, majority (27) were macerated $(71 \%)$. Prematurity was most commonly associated with early NND.

\section{DISCUSSION}

Perinatal death audit contributes remarkably to the prevention of perinatal deaths. Regular perinatal death audit is essential in an institution to find out the avoidable factors in related to perinatal deaths. The avoidable factors may be related to antenatal, intrapartum or neonatal management. Indirect factors like maternal age and parity, social factors, quality of antenatal care are also equally important. In the present series, the Perinatal mortality rate was 29.4 per 1000 births This rate seems to be high as compared to developed countries like Japan where it is less than 10 (WHO 1989). ${ }^{2}$ In south Asia, the estimate of PMR was as high as 87 per 1000 births, where as for Asia it was 59 per 1000 births and for developed countries it was 18 per 1000 births $1989 .{ }^{9}$ So in our study, PMR seems to be lower than the south Asian average. In the Maternity hospital of Kathmandu, the PMR was 34.3 per 1000 births in rate $1997 . .^{10}$

PMR was found out to be almost double in adolescent mothers i.e. 51.1 per 1000 births. Antenatal check up is another factor influencing the Perinatal outcome, as $46.7 \%$ of cases of Perinatal deaths have not attended ANC. 27 cases i.e. $60 \%$ out of 45 perinatal deaths were macerated still births, where the attendance to hospital was already to late. At the Zaria hospital where the PMR was 103 per 1000, 67\% were still births and in three further of these the fetus had been dead prior to the admission. ${ }^{11}$

Premature births and low birth weight babies are undoubtedly the important causes of perinatal death as shown in tables $3 \&$ 4. Perinatal mortality in premature babies was $173.2 / 1000$ births. $48.9 \%$ (22 cases) out of 45 perinatal deaths were premature births. In Mehta's ${ }^{5}$ study in India in 1983, prematurity was seen in $17.9 \%$. The rate of low birth weight babies was $31.7 \%$, in whom Perinatal mortality rate was $77 /$ 1000 births $88.9 \%$ (40 cases) out of 45 perinatal deaths were in low birth weight babies. These findings are consistent those in Maternity Hospital, i.e. $80.5 \%$ of Perinatal deaths occurred in low birth wt. babies and preterm babies accounted for $74.3 \%$ of early neonatal deaths. ${ }^{10}$ In a multicentric South East Asian regional study, the PMR varied from 120-150 per 1000 births when the birthweight was below $2.5 \mathrm{~kg}$ compared to $16-30$ per 1000 births when birth wt. was $>2.5 \mathrm{~kg}$, as reported by Perera \&Lwin in $1984 .^{6}$

Gross congenital abnormality was found in two cases of still births, i.e. $4.4 \%$ of Perinatal deaths, this finding is similar to that reported in Indonesian study. ${ }^{6}$

The antepartum fetal deaths were mainly due to hypertensive disease of pregnancy-13.3\% (6 cases) and abruptio placenta$11.1 \%$ (5 cases).

In 18 cases $(40 \%)$, direct cause could not be found. Studies done in India $^{5}$ and Indonesia ${ }^{6}$ have shown unknown causes 
for perinatal mortality in $32.6 \%$ \& and $32.5 \%$ respectively. This indicates the need for further detail \& prospective studies to search for avoidable factors.

\section{CONCLUSION AND RECOMMENDATIONS}

It is clear from the results of present study that perinatal outcome is poor in adolescent as well as elderly mothers. So efforts should be directed to educate adolescent mothers to try to prevent adolescent pregnancy and late pregnancy as well.

Low birth weight and premature babies had maximum perinatal mortality rate, so need for regular ANC for maternal and fetal well being, nutritional supplements, importance of rest, basic antenatal investigations should be emphasized.

All expectant mothers must attend early, regular and quality ANC, screened for high risks, individualized specific care should be given to high risks mothers. Especially those with pregnancy induced hypertension, antepartum haemorrage and infections must be managed properly.

Health education should emphasize the need for booking , awareness of common complications, warning symptoms of premature labor, avoidance of drugs and infections in early pregnancy to minimize congenital anomalies, malpresentations and cephalo pelvic disproportion should be diagnosed early and managed properly.

Regular perinatal death audit is required and the coordination between hour coordination between departments of obstetrics, neonatology and pathology should be maintained to collect important data on perinatal deaths. Confidential enquiries would be useful to show the scope for prevention through clinical practice. It is essential to understand the implications and limitations because it should be an audit of perinatal management and not just the perinatal outcome. A genuine clinical audit would imply a flexible attitude towards a change and a professional mechanism should be evolved for implementation.

\section{REFERENCES}

1. YuY.HV ctor.Peri natal nortal i tyand norbi d tyaud t.Soweri $r$, Fi rst Nati onal Conf er ence of Peri natal Soci ety of Nepal : P97. 1- 11

2. WHO Regi onal esti nates of Peri natal nortal ity, neekl y Epi dennol ogi cal Reports. P89: WHO Geneva.

3. W'ggl esuorth J. S. Moni toring Peri natal nortal ity : A Pathophysi ol ogi cal approach.Lancet P80: i i : 684- 86.

4. EdouvardL andA bernan, ENati onal trends i ncerti fi edcauses of peri natal nortal i ty. P68- 78. Br. J . Obst. Gyne. 1980: 87: 833- 36.

5. MehtaA C Peri natal nortal i ty i nI nd a.J . Obs. Gyne.I ndi a P83; 33: 721

6. PereraT, Lw nKMPeri natal nortal i tyand norbi di tyi ncl ud ng I owbi rth vei ght: ASoutheast Asi a Regi onal prof i I e VHDSEAPO Regi onal Heal th papers Nb. 3 P84. WWD Regi onal offi ce, NewDel hi .

7. MacFarl ane, A, Col e S. Hey E. Conpari son of data from regi onal Peri natal nortal i ty surveys. Br.J. Obs. Gyne. 1986; 93:1224- 32.

8. Lopez ADCauses of Deaths- an assessnent of gl obal patterns of nortal i ty around P85 worl d Heal th St ati sti cs Quart, P90; 43: 91103.

9. Bel sey, MA Royst on E Mternal and I nf ant Mortal i ty:Agl obal revi ew 1989: WWO, Geneva.

10. Manandhar DS. An Qvervi ewof Peri natal deathaudi t i n Nepal . Souveni $r$, Fi rst Nati onal Conf erence of PESON P97: 1- $\mathbf{B}$.

11. Harri son, KA, Li ster UG, Possi ter, CE. Peri natal nortal i ty i n Zari a. Br. J . Obs. Gyne. 1985; 92: Suppl .5: 86- 99. 